\title{
Volume Preload versus Ephedrine Infusion for Prevention of Hypotension Due to Spinal Anesthesia for Cesarean Section
}

\author{
Heba Omar Ahmed*, Mona Hossam, Abdelmonem Adel \\ Faculty of Medicine, Cairo University, Giza, Egypt \\ Email:"hebaomar2@yahoo.com, monahossam29@yahoo.com, abdelmonemadel87@gmail.com
}

Received 22 February 2016; accepted 28 March 2016; published 31 March 2016

Copyright (C) 2016 by authors and Scientific Research Publishing Inc.

This work is licensed under the Creative Commons Attribution International License (CC BY). http://creativecommons.org/licenses/by/4.0/

\section{(c) (i) Open Access}

\begin{abstract}
Background: Spinal anesthesia is used for $95 \%$ of planned cesarean sections in the United States. It provides a fast and profound sensory and motor block. However, hypotension is a very common complication of spinal anesthesia during cesarean section, causing significant morbidity and mortality. It could be associated with severe nausea, vomiting and even unconsciousness and pulmonary aspiration in the mother and for the baby, hypoxia, acidosis, and neurological injuries may result. Methodology: Fifty patients were randomly allocated into two groups. Group I (F group) patients received preloading with $15 \mathrm{ml} / \mathrm{kg}$ Ringer lactate before induction of spinal anesthesia, and group II (E group) patients received IV ephedrine $\left(5 \mathrm{mg}\right.$ in $1^{\text {st }}$ minute after spinal anesthesia and $5 \mathrm{mg}$ in the $\mathbf{2}^{\text {nd }}$ minute and $1 \mathrm{mg}$ every minute after that for 15 minutes). Results: A statistically significant difference in the incidence of hypotension between group $F(48 \%)$ and group $E$ (24\%) was seen, (p-value 0.03). Regarding side effects, the incidence of nausea and vomiting was higher in the group F (20\%) when compared to group E (12\%), (p-value 0.23$)$. Conclusions: We concluded that IV infusion of ephedrine after induction of spinal anesthesia was more effective than crystalloid preloading in a prevention of hypotension in parturient undergoing cesarean section and did so without causing significant tachycardia.
\end{abstract}

\section{Keywords}

Hypotension, Spinal, Cesarean Section, Ephedrine

\footnotetext{
${ }^{*}$ Corresponding author.
}

How to cite this paper: Ahmed, H.O., Hossam, M. and Adel, A. (2016) Volume Preload versus Ephedrine Infusion for Prevention of Hypotension Due to Spinal Anesthesia for Cesarean Section. Open Journal of Anesthesiology, 6, 37-44. 


\section{Introduction}

Anesthesia of cesarean delivery should take in consideration safety of the mother and fetus. Regional anesthesia is used for 95\% of planned cesarean deliveries in the United States [1]. Spinal anesthesia has many advantages as it provides fast, profound sensory and motor block [2] and adequate muscle relaxation [3], better airway control with reduced risk of airway obstruction or aspiration of gastric contents. Post-operative deep vein thrombosis and pulmonary emboli are less common following spinal anesthesia [4], due to earlier ambulation and discharge.

However, spinal anesthesia has its complications. The most common complication of spinal anesthesia for cesarean section is hypotension [5] which can cause significant morbidity and mortality [6], as it may cause serious complications for the mother as nausea, vomiting, unconsciousness and pulmonary aspiration, and for the baby as hypoxia, acidosis, and neurological injuries [7]. Hypotension occurs due to sympathetic nervous system blockade, leading to decreased systemic vascular resistance and peripheral pooling of blood which reduces cardiac output [8].

The incidence of hypotension is higher in cesarean sections due to cardiac changes of the parturient, compression of inferior vena cava by hypertrophic uterus and developing of collateral venous plexus circulation in the epidural space, leading to a decrease in the amount of cerebrospinal fluid (CSF) in the lumbosacral area and higher cephalad spread of local anesthetics [9].

Different techniques have been tried to reduce hypotension incidence and severity. This includes the routine use of lateral uterine displacement [10], infusion of up to 2 liters of fluids for intravascular volume expansion, which may reduce the risk of hypotension but does not eliminate it [11], and use of vasopressor as ephedrine which may be an effective alternative for hypotension prevention [12]. Ephedrine is a sympathomimetic agent, non-catecholamine-mediated, which directly stimulates alpha and beta adrenergic receptors and predominantly indirectly, producing its effects through releasing norepinephrine from nerve endings in the autonomous nervous system [12].

The aim of this study was to compare the efficacy of ephedrine infusion versus crystalloid preloading, in reducing the incidence of hypotension during spinal anesthesia for cesarean section.

\section{Patients and Methods}

After approval of the Medical Ethical Committee of Kasr El-Aini Hospital, Faculty of Medicine, Cairo University and obtaining informed written consent from each patient, this prospective randomized study was conducted at Kasr El-Aini Hospital from March 2014 to September 2014, on 50 adult pregnant female patients came for delivery by cesarean section. Inclusion criteria were age between 20 - 45 years old, with body mass index (BMI) between 25 and 40, height from 160 to $170 \mathrm{~cm}$, and classified by the American Society of Anesthesiologist (ASA) physical status to class I or class II. Exclusion criteria were patients who refused spinal anesthesia, with a history of allergic reactions to local anesthetics and opioids, patients with coagulopathy (due to blood disease, liver diseases or on anticoagulants), patients with severe cardiac, respiratory, hepatic or renal disease, and patients with pre-eclampsia and eclampsia.

The primary outcome was to detect the incidence of hypotension after spinal anesthesia in pregnant female coming for caesarean section, wether it effectively prevented by prophylactic fluid infusion or ephedrine infusion.

The secondary outcome was to detect other complications like nausea \& vomiting, chest symptoms and number of ephedrine doses to treat hypotension.

Patients were assessed by detailed history taking, physical examination and routine preoperative investigations (e.g. CBC, PT, PTT, INR, liver function tests, kidney function tests and fasting blood sugar) for evaluation of the patient medical status. No premedication was given.

On arrival to the operating room, continuous monitoring with electrocardiography, non-invasive blood pressure, and pulse oximetry was started. Baseline systolic blood pressure, heart rate, and arterial oxygen saturation were recorded. A suitable peripheral vein was cannulated with (18G) peripheral cannula.

Patients were randomly divided into two equal groups of 25 patients each (by closed envelope method);

Group F: Those who received crystalloid preloading $15 \mathrm{ml} / \mathrm{kg}$ (Ringer lactate) before the procedure.

Group E: Those who received prophylactic (before hypotension occurrence) ephedrine intravenously $25 \mathrm{mg}$ in $50 \mathrm{ml}$ saline as follow, $5 \mathrm{mg}$ at $1^{\text {st }}$ and $2^{\text {nd }}$ minute and then infusion of $1 \mathrm{mg} / \mathrm{min}$ over 15 minutes after block. 
(Ephedrine ampoule $1 \mathrm{ml}$ = $25 \mathrm{mg}$ Ephedrine Hydrochloride, manufactured by CID company—Egypt, Exp. date 3/2016)

The patient was in sitting position, sterilization by Povidone Iodine was done. Dural puncture was performed at interspace L3-L4 with a 22 gauge spinal needle after infiltration of the skin at the site of lumbar puncture with $2 \mathrm{~cm}$ of lidocaine $1 \%$. All the patients received the same amount of local anesthetic $2 \mathrm{ml}$ of $0.5 \%$ heavy Bupivacaine + fentanyl $(25 \mu \mathrm{g})$. Then the patient was placed in the left lateral position by using a wedge under the right hip with slight elevation of the head; oxygen nasal cannula was used 4 litres/minute. The level of sensory block was assessed by loss of pinprick sensation (all patients included in the study had sensory level T4-T5).

Heart rate and systolic blood pressure were measured noninvasively at $1 \mathrm{~min}$ after spinal anesthesia, and then every 3 minutes for the first 30 minutes then every 5 minutes for 30 minutes then after 30 minutes. $\mathrm{O}_{2}$ saturation was recorded by pulse oximetry continuously and recorded every 30 minutes.

An infusion of Ringer lactate at a rate of $2 \mathrm{ml} / \mathrm{Kg} / \mathrm{hr}$ was given during the whole surgical procedure.

Hypotension (20\% decrease in SBP from the baseline) was treated immediately by $5 \mathrm{mg}$ bolus IV ephedrine every 3 minutes until SBP returned to normal value in all groups.

Oxytocin administered after fetus delivery (10 units in $500 \mathrm{ml}$ lactated Ringer) in both groups.

Nausea, vomiting and chest symptoms (dyspnea and tachypnea) were also recorded. Nausea and vomiting treated with $10 \mathrm{mg}$ metoclopramide.

Postoperatively, all patients in the two groups were assessed for Heart rate, Blood pressure noninvasively and oxygen saturation and were recorded postoperatively after 30 minutes. Complications as hypotension, nausea, vomiting and chest symptoms (dyspnea or tachypnea) were also recorded.

\section{Statistics}

A prospective power study showed that a sample size of 30 per study group will have $80 \%$ power at the $5 \%$ significance level to detect a difference of $50 \%$ in the incidence of hypotension in the E group compared with $\mathrm{F}$ group assuming a baseline incidence of $80 \%$ as reported by a published study of a similar patient group.

According to the type of obtained data were presented as mean \pm standard deviation or frequencies and percentages as appropriate.

Comparisons were performed using Student t-test, Chi-square test, or analysis of variance (ANOVA) according to the type of variance. Data was analyzed using a statistical package of social studies SPSS version 20 (IBM Corp. USA) and Microsoft Excel 2013. P value $\leq 0.05$ was considered statistically significant.

\section{Results}

Fifty patients were recruited for this study and randomly allocated into two groups, F group (fluid) and E group (ephedrine). Demographic Data including age, BMI, height and parity, there were no significant differences the two groups (Table 1 ).

Regarding systolic blood pressure, there was higher in E group when compared to F group; however results was not statistically significant except at $4 \mathrm{~min}$, there was (110.2 \pm 15.5$)$ in ephedrine group when compared to fluid group (103.9 \pm 8.8) P value 0.04 and at 22 min post spinal, there was (117.8 \pm 10.8$)$ in ephedrine group when compared to fluid group (112.1 \pm 11.8$) \mathrm{P}$ value 0.04 (Table 2).

On the other hand heart rate was higher in E group when compared to F group. However, it was not statistically significant, $\mathrm{P}$ value more than 0.05 (Figure 1 ).

Table 1. Demographic data of patients included in the study.

\begin{tabular}{cccc}
\hline & F group & E group & P value \\
\hline Age & $27(20-39)$ & $27(20-40)$ & $\mathbf{0 . 2 1}$ \\
BMI & $35.2 \pm 1.7$ & $35.3 \pm 1.7$ & $\mathbf{0 . 4 0}$ \\
Height & $162.7 \pm 2.9$ & $163.3 \pm 3.7$ & $\mathbf{0 . 2 4}$ \\
Parity & $2(0-4)$ & $1(0-5)$ & $\mathbf{0 . 4 4}$ \\
\hline
\end{tabular}

Data represented as Mean \pm SD or median (range). 
Table 2. Systolic BP (mm hg).

\begin{tabular}{|c|c|c|c|}
\hline & F group & E group & $P$ value \\
\hline Baseline & $122.6 \pm 7.8$ & $119 \pm 9.9$ & 0.09 \\
\hline $1 \mathrm{~min}$ & $116.3 \pm 12.3$ & $116.4 \pm 12.3$ & 0.48 \\
\hline $4 \mathrm{~min}$ & $103.9 \pm 8.8$ & $110.2 \pm 15.5$ & 0.04* \\
\hline $7 \mathrm{~min}$ & $110.6 \pm 12.8$ & $111.7 \pm 13.7$ & 0.4 \\
\hline $10 \mathrm{~min}$ & $111.7 \pm 10.1$ & $112.4 \pm 13.2$ & 0.4 \\
\hline $13 \mathrm{~min}$ & $108.7 \pm 6.6$ & $110.4 \pm 12.0$ & 0.3 \\
\hline $16 \min$ & $111.4 \pm 10.2$ & $115.6 \pm 10.9$ & 0.08 \\
\hline $19 \mathrm{~min}$ & $111.9 \pm 10.9$ & $113.7 \pm 13.5$ & 0.3 \\
\hline $22 \mathrm{~min}$ & $112.1 \pm 11.8$ & $117.8 \pm 10.8$ & 0.04* \\
\hline $25 \mathrm{~min}$ & $113.3 \pm 8.6$ & $116.4 \pm 9.7$ & 0.1 \\
\hline $28 \mathrm{~min}$ & $113.3 \pm 12.5$ & $117.5 \pm 11.9$ & 0.08 \\
\hline $31 \mathrm{~min}$ & $114.3 \pm 8.3$ & $118.1 \pm 9.7$ & 0.0 \\
\hline $36 \mathrm{~min}$ & $112.4 \pm 9.7$ & $116 \pm 9$ & 0.0 \\
\hline $41 \mathrm{~min}$ & $115.1 \pm 6.1$ & $116.2 \pm 6.0$ & 0.3 \\
\hline $46 \mathrm{~min}$ & $113.4 \pm 6.8$ & $116.4 \pm 9.8$ & 0.1 \\
\hline $51 \mathrm{~min}$ & $117.0 \pm 5.4$ & $118 \pm 6.7$ & 0.3 \\
\hline $56 \mathrm{~min}$ & $119.1 \pm 9$ & $119.7 \pm 6.2$ & 0.4 \\
\hline $61 \mathrm{~min}$ & $122.5 \pm 6.2$ & $122.9 \pm 5.2$ & 0.4 \\
\hline $90 \mathrm{~min}$ & $120.5 \pm 6.5$ & $121.4 \pm 7.59$ & 0.3 \\
\hline
\end{tabular}

Data represented as Mean $\pm \mathrm{SD}, *=\mathrm{P}$ value $\leq 0.05$.

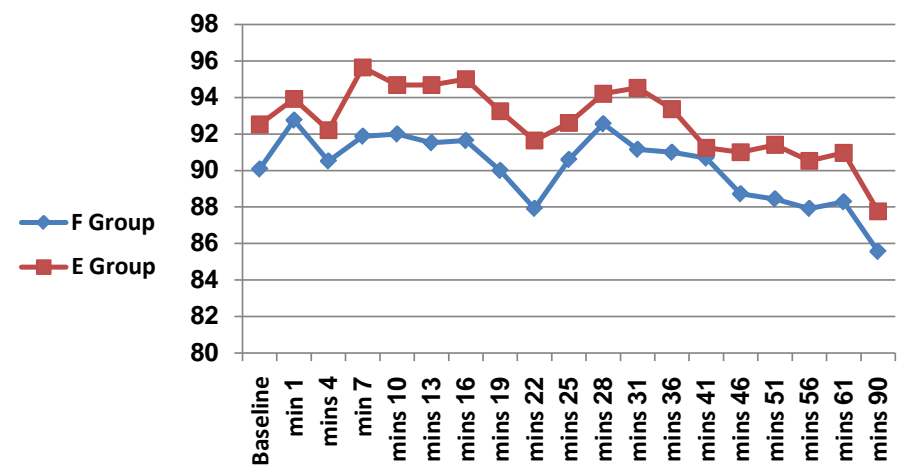

Figure 1. Heart rate trends.

About the incidence of complications, the incidence of hypotension was significantly higher in F group (12/25) when compared to E group (6/25) P value 0.03. The incidence of nausea and vomiting was higher in $\mathrm{F}$ group when compared to E group, but it was not statistically significant, and there were no chest symptoms in both groups (Table 3).

In addition, oxygen saturation changes throughout study time did not show any statistically significant differences between the two groups (Table 4).

As regard number of ephedrine boluses required to correct hypotension were significantly lower in ephedrine group $(0.3 \pm 0.54)$ when compared to fluid group $(0.6 \pm 0.8) \mathrm{P}$ value $0.046 *$ (Table 5).

\section{Discussion}

Regarding caesarean section, spinal anesthesia is considered safe as compared to general anesthesia. However spinal anesthesia has its complications. Hypotension following spinal anesthesia during caesarean section is very 
Table 3. Incidence of complications.

\begin{tabular}{cccc}
\hline & F group & E group & P value \\
\hline Hypotension & $12 / 25(48 \%)$ & $6 / 25(24 \%)$ & $0.03^{*}$ \\
Nausea \& Vomiting & $5 / 25(20 \%)$ & $3 / 25(12 \%)$ & 0.23 \\
Chest symptoms & $0 / 25(0 \%)$ & $0 / 25(0 \%)$ & 0 \\
\hline
\end{tabular}

Data represented as number of positive cases/total number of patients $(\%), *=\mathrm{P}$ value $\leq 0.05$.

Table 4. Oxygen saturation.

\begin{tabular}{ccccc}
\hline & F group & E group & P value & \\
Baseline & $98.5 \pm 0.8$ & $98.3 \pm 0.7$ & $\mathbf{0 . 2 3}$ & $\mathbf{0 . 2 6}$ \\
$30 \mathrm{~min}$ & $99.7 \pm 0.5$ & $99.8 \pm 0.4$ & $\mathbf{0 . 5}$ & $\mathbf{0 . 1 1}$ \\
$60 \min$ & $99.8 \pm 0.4$ & $98.8 \pm 0.4$ & 0.6 & \\
\hline
\end{tabular}

Data represented as Mean \pm SD.

Table 5. Number of ephedrine boluses.

\begin{tabular}{cccc}
\hline & F group & E group & P value \\
\hline Number of ephedrine boluses & $0.6 \pm 0.8$ & $0.3 \pm 0.54$ & $0.046^{*}$ \\
\hline
\end{tabular}

Data represented as Mean \pm SD. * $=$ P value $\leq 0.05$.

frequent, and if not prevented, it can cause complication for the mother and the fetus [13].

Intravenous preloading is the most common non-pharmacological method in a prevention of hypotension. Early studies showed impressive results [14] and it became established routine. However, the efficacy of preloading has been questioned by recent controlled studies. Some had shown that it is effective in reducing the severity of hypotension [15], and some showed that preloading has limited effect on the incidence of hypotension [16].

Vercauteren et al. [17] considered ephedrine is the vasopressor of choice for hypotension prevention after spinal anesthesia during cesarean section because of its ability tokeep uteroplacental blood flow maintained as ephedrine's action is considered mainly indirect, through stimulating norepinephrine release from sympathetic nerve endings and the uteroplacental circulation is largely devoid of direct sympathetic innervation, so it is considered resistant to the vasoconstrictive effects of ephedrine.

Regarding the route of ephedrine administration, Rout et al. 1992 [18] stated that it is difficult to predict both absorption and peak effect of intramuscular ephedrine and also observed reactive hypertension, especially if spinal anesthesia was not successful.

Prophylactic IV ephedrine administered either by infusion or multiple bolus injections has been considered the gold standard for preventing and treating hypotension [19]. The effect of an IV bolus of ephedrine on arterial pressure is transient, and it lasts for only 10 - 15 minutes [20].

In our study, we compared the efficacy of fluid preloading with $15 \mathrm{ml} / \mathrm{Kg}$ lactated Ringer (F group) versus prophylactic IV ephedrine infusion without fluid preload (E group) for prevention of hypotension after spinal anesthesia for cesarean section.

There was no significant difference in the distributions by dermatome levels for patients of both groups ranged between T4-T5 upper sensory level, so patients were having similar degrees of sympathetic block. Therefore, the differences in the incidence of hypotension observed between the two groups to be due to presence or absence of preventive measures only.

Our results showed that SBP was higher in ephedrine group when compared to the fluid group, and it was statistically significantly higher at $4^{\text {th }}$ and $21^{\text {st }}$ minutes post spinal. Though heart rate was higher in E group when compared to F group, there was no significant difference in the heart rate between the two groups. This could be explained both by the effect of rescue ephedrine and by baroreceptor-mediated reflex increases in heart rate in patients who became hypotensive. 
Our study showed that the incidence of hypotension was significantly lower in E group when compared to $\mathrm{F}$ group, $\mathrm{P}$ value (0.03).

Also, the incidence of nausea and vomiting was lower in the E group when compared with F group. However, this was not statistically significant.

A number of ephedrine boluses required to correct hypotension were significantly lower in E group (0.6 \pm 0.8$)$ when compared to F group (0.3 \pm 0.54$)$, P value (0.046).

In consistence with our results, Gajraj et al. [21] compared the efficacy of ephedrine infusion with crystalloid administration for reducing the incidence of hypotension following spinal anesthesia for patients underwent postpartum tubal ligations under spinal anesthesia, patients were randomly allocated into groups, either receiving $15 \mathrm{~mL} / \mathrm{kg}$ of crystalloid (crystalloid group) or ephedrine infusion (infusion group) at the same rate as in our study. He found that hypotension incidence was significantly higher in the crystalloid group compared to the infusion group $(\mathrm{P}<0.05)$. There was no significant difference between the two groups regarding the level of anesthesia or maximal heart rate, and hypertension did not occur in either group which is similar to our result. But there was no statistically significant difference in the incidence of nausea and vomiting. This is, in contrast, to our study, which may be due different type of patient (pregnant versus non-pregnant) and different type of surgical procedure (cesarean section versus postpartum tubal ligation).

Bhovi et al. [22] studied the efficacy of ephedrine for preventing hypotension in patients undergoing caesarean section under spinal anesthesia. Patients were randomly allocated to receive either ephedrine infusion $50 \mathrm{mg}$ in $500 \mathrm{ml}$ of Ringer's Lactate immediately after administration of spinal anesthesia at a rate of $50 \mathrm{ml} / \mathrm{min}$ for first 2 minutes, and $10 \mathrm{ml} / \mathrm{min}$ for next $18 \mathrm{~min}$ or $20 \mathrm{ml} / \mathrm{kg}$ of Ringer's Lactate solution as a preloading solution before the subarachnoid block. The study revealed that the incidence of hypotension was significantly higher in the patient group who received fluid preload (60\%) compared with (12\%) in the patients group who received ephedrine infusion. The incidence of hypotension in the ephedrine group in this study was (12\%) in comparison with our study the incidence of hypotension in the ephedrine group was (24\%), this difference may be due to different doses of ephedrine used and different volume of infusion.

In contrast to our study; Thiangtham et al. [23] performed a concealed randomized study, 96 parturient were divided into two groups, the study group received ephedrine $18 \mathrm{mg}$ ( $3 \mathrm{ml}$ ) added to $100 \mathrm{ml}$ normal saline, while the control group received $3 \mathrm{ml}$ of normal saline instead of ephedrine given by intravenous continuous infusion over 10 minutes. All patients had the preloading fluid with lactated Ringer's solution $20 \mathrm{ml} / \mathrm{kg} 10$ minutes before spinal block which was done with $0.5 \%$ hyperbaric bupivacaine mixed with preservative-free morphine. He found that there was no statistically significant difference in the incidence of hypotension between the two groups. The incidence of hypotension was $93.8 \%$ in the control group and $85.4 \%$ in the study group. This may be due to the small dose of ephedrine used and different infusion rate.

Although ephedrine increases uteroplacental blood flow, there is evidence of increased fetal acidosis associated with the use of ephedrine. The most accepted explanation is that ephedrine increases the metabolic rate of the fetus. A study by Cooper et al. [24] offers evidence that this may be the case. They used an index to assess where the umbilical artery acidosis was occurring. The $\mathrm{pCO}_{2}$ of the umbilical artery was measured, and the $\mathrm{pCO}_{2}$ of the umbilical vein was subtracted from it. They assumed that this value would be large if acidosis were developed in the fetus. And they found that a low umbilical artery $\mathrm{pH}$ was strongly correlated with a high value of umbilical artery $\mathrm{pCO}_{2}$ minus umbilical vein $\mathrm{pCO}_{2}$ in the ephedrine group. They also found that this index was related to ephedrine dose. These data suggest that ephedrine increases the metabolic rate of the fetus.

IN contrast to our study; Ozdamier I. et al. [25] had made a randomized, double-blinded study to determine the effect of $0.5 \mathrm{mg} / \mathrm{kg}$ intravenous ephedrine infusion for hypotension prevention in the cesarean section following spinal anesthesia, and if it has an effect on neonatal outcome and umbilical artery PH. All patients received preloading with $15 \mathrm{ml} / \mathrm{kg}$ lactated ringer before the spinal block. Then patients were randomly allocated into two groups: ephedrine group, in which patients were injected with $0.5 \mathrm{mg} / \mathrm{kg}$ ephedrine intravenously over 60 seconds, and control group, in which patients were injected with saline. He found that there were significant lower incidences of hypotension and nausea and vomiting in the ephedrine group compared to the control group. Neonatal findings were similar in both groups. There was no significant difference in umbilical artery ph, (7.34 \pm $0.5)$ in the ephedrine group and (7.32 \pm 0.3$)$ in the control group. This suggests that the prophylactic dose of intravenous $0.5 \mathrm{mg} / \mathrm{kg}$ ephedrine given at the time of spinal anesthesia after preload with crystalloid fluid reduces the incidence of hypotension with no effect on neonatal outcome or umbilical artery Ph.

Limitations in our study: The umbilical artery PH and neonatal APGAR score were not measured to dem- 
onstrate the effect of ephedrine on an acid-base status of the fetus and whether it is clinically significant or not.

Recommendations for further studies: To compare neonatal APGAR score and fetal acid-base status in both groups.

\section{Conclusion}

We conclude that prophylactic IV ephedrine infusion is more effective than fluid preload in a prevention of hypotension due to spinal anesthesia factors for a cesarean section without causing significant tachycardia or hypertension.

\section{References}

[1] Bucklin, B.A., Hawkins, J.L., Anderson, J.R. and Ullrich, F.A. (2005) Obstetric Anesthesia Workforce Survey: TwentyYear Update. Anesthesiology, 103, 645-653. http://dx.doi.org/10.1097/00000542-200509000-00030

[2] Hawkins, J.L., Arens, J.F., Bucklin, B.A., et al. (2007) Practice Guidelines for Obstetric Anesthesia: An Updated Report by the American Society of Anesthesiologists Task Force on Obstetric Anesthesia. Anesthesiology, 106, 843-863. http://dx.doi.org/10.1097/01.anes.0000264744.63275.10

[3] Campbell, J. and Sultan, P. (2009) Regional Anaesthesia for Caesarean Section: A Choice of Three Techniques. British Journal of Hospital Medicine (London), 70, 605. http://dx.doi.org/10.12968/hmed.2009.70.10.44637

[4] Kuczkopwski, K.M., Reisner, L.S. and Lin, D. (2009) Anesthesia for Cesarean Section. In: Chestnut, D.H., Polley, L.S., Tsen, L.C. and Wong, C.A., Eds., Chestnut's ObstetricAnesthesia: Principles and Practice. 4th Edition, Mosby, Philadelphia, 422-425.

[5] Carvalho, B., Coleman, L., Saxena, A., Fuller, A.J. and Riley, E.T. (2010) Analgesic Requirements and Postoperative Recovery after Scheduled Compared to Unplanned Cesarean Delivery: A Retrospective Chart Review. International Journal of Obstetric Anesthesia, 19, 10-15. http://dx.doi.org/10.1016/j.ijoa.2009.02.012

[6] Carpenter, R.L., Caplan, R.A., Brown, D.L., et al. (1992) Incidence and Risk Factors for Side Effects of Spinal Anesthesia. Anesthesiology, 76, 906-916. http://dx.doi.org/10.1097/00000542-199206000-00006

[7] Cyna, A.M., Andrew, M., Emmett, R.S., Middleton, P. and Simmons, S.W. (2006) Techniques for Preventing Hypotension during Spinal Anaesthesia for Caesarean Section. Cochrane Database of Systematic Reviews, 18, CD002251. http://dx.doi.org/10.1002/14651858.cd002251.pub2

[8] Bhagat, H., Malohtra, K., Ghildyal, S.K. and Srivastava, P.C. (2004) Evaluation of Preloading and Vasoconstrictors as a Combined Prophylaxis for Hypotension during Subarachnoid Anaesthesia. Indian Journal of Anaesthesia, 48, 299303.

[9] Higuchi, H., Hirata, J., Adachi, Y. and Kazama, T. (2004) Influence of Lumbosacral Cerebrospinal Fluid Density, Velocity, and Volume on Extent and Duration of Plain Bupivacaine Spinal Anesthesia. Anesthesiology, 100, 106-114. http://dx.doi.org/10.1097/00000542-200401000-00019

[10] Clark, S.L., Cotton, D.B., Pivarnik, J.M., Lee, W., Hankins, G.D., Benedetti, T.J. and Phelan, J.P. (1991) Position Change and Central Hemodynamic Profile during Normal Third-Trimester Pregnancy and Post Partum. American Journal of Obstetrics \& Gynecology, 164, 883-887. http://dx.doi.org/10.1016/S0002-9378(11)90534-1

[11] Jackson, R., Reid, J.A. and Thorburn, J. (1995) Volume Preload Is Not Essential to Prevent Spinal Induced Hypotension at Cesarean Section. British Journal of Anaesthesiology, 75, 262-265. http://dx.doi.org/10.1093/bja/75.3.262

[12] Kang, Y.G., Abouleish, E. and Caritis, S. (1983) Prophylactic Intravenous Ephedrine Infusion during Spinal Anesthesia for Cesarean Section. Anesthesia \& Analgesia, 61, 839-842. http://dx.doi.org/10.1097/00132586-198310000-00051

[13] Mercier, F.J., Bonnet, M.P., De la Dorie, A., Moufouki, M., Banu, F., Hanaf, A., Edouard, D. and Roger-Christoph, S. (2007) Spinal Anaesthesia for Caesarean Section: Fluid Loading, Vasopressor and Hypotension. Annales Françaises d'Anesthésie et de Réanimation, 26, 688-693. http://dx.doi.org/10.1016/j.annfar.2007.05.003

[14] Mojica, J.L., Meléndez, H.J. and Bautista, L.E. (20022) The Timing of Intravenous Crystalloid Administration and Incidence of Cardiovascular Side Effects during Spinal Anesthesia: The Results from a Randomized Controlled Trial. Anesthesia \& Analgesia, 94, 432-437.

[15] Clark, R.B., Thompson, D.S. and Thomson, C.H. (1976) Prevention of Spinal Hypotension Associated with Caesarean Section. Anesthesiology, 45, 670-674. http://dx.doi.org/10.1097/00000542-197612000-00018

[16] Jackson, R., Reid, J.A. and Thorburn, J. (1995) Volume Preloading Is Not Essential to Prevent Spinal-Induced Hypotension at Caesarean Section. British Journal of Anaesthesia, 75, 262-265. http://dx.doi.org/10.1093/bja/75.3.262

[17] Vercauteren, M.P., Coppejans, H.C., Hoffmann, V.H. and Mertens, E. (2009) Prevention of Hypotension by A Single 5-mg Dose of Ephedrine during Spinal Anesthesia in Prehydrated Caesarean Delivery Patients. Anesthesia \& Analge- 
sia, 90, 324-327.

[18] Rout, C.C., Rocke, D.A., Brijball, R. and Koovarjee, R.V. (1992) Prophylactic Intramuscular Ephedrine Prior to Caesarean Section. Anaesthesia and Intensive Care, 20, 448-452.

[19] Kee, W.D.N., Khaw, K.S., Lee, B.B., Lau, T.K. and Gin, T. (2009) A Dose-Response Study Ofprophylactic Intravenous Ephedrine for the Prevention of Hypotension during Spinal Anesthesia for Caesarean Delivery. Anesthesia \& Analgesia, 90, 1390-1395. http://dx.doi.org/10.1097/00000539-200006000-00024

[20] Hollmen, A.J., Joppila, R., Albright, G.A., Jouppila, P., Vierola, H. and Koivula, A. (1984) Intervillous Blood Flow during Caesarean Section with Prophylactic Ephedrine and Epiduralanesthesia. Acta Anaesthesiologica Scandinavica, 28, 396-400.

[21] Gajraj, N.M. (1993) Comparison of an Ephedrine Infusion with Crystalloid Administration for Prevention of Hypotension during Spinal Anesthesia. Anesthesia \& Analgesia, 76, 1023-1026. http://dx.doi.org/10.1213/00000539-199305000-00020

[22] Madhusoodana, R. and Bhovi, A. (2014) Comparitive Study of Ephedrine Infusion with the Preload of Crystalloids for Prevention of Hypotension during Spinal Anaesthesia for Elective Caesarean Section. Indian Journal of Applied Research, 4, 2249-2255.

[23] Thiangtham, K. and Asampinwat, T. (2009) Intravenous Ephedrine Infusion for Prophylaxis of Hypotension during Spinal Anesthesia for Cesarean Section. Songklanagarind Medical Journal, 27, 291-300.

[24] Cooper, D.W., Carpenter, M., Mowbray, P., Desira, W.R., Ryall, D.M. and Kokri, M.S. (2002) Fetal and Maternal Effects of Phenylephrine and Ephedrine during Spinal Anesthesia for Cesarean Delivery. Anesthesiology, 97, 1582-1590. http://dx.doi.org/10.1097/00000542-200212000-00034

[25] Kol, I.O., Kaygusuz, K., Gursoy, S., Cetin, A., Kahramanoglu, Z., et al. (2009) The Effects of Intravenous Ephedrine during Spinal Anesthesia for Cesarean Delivery: A Randomized Controlled Trial. Journal of Korean Medical Science, 24, 883-888. http://dx.doi.org/10.3346/jkms.2009.24.5.883 